\title{
COVERAGE AND INVARIANCE FOR THE BIOLOGICAL CONTROL OF PESTS IN A MEDITERRANEAN GREENHOUSE
}

\author{
Miguel Lloret-Climent, Josué-Antonio Nescolarde-Selva*, Lucía González-Franco \\ Department of Applied Mathematics, University of Alicante, Alicante, Spain
}

${ }^{*}$ Corresponding author: email: josue.selva@ua.es, Telephone.0034680418381, Fax number. 0034965909707

\begin{abstract}
A major problem related to the treatment of ecosystems is that they have no available mathematical formalization. This implies that many of their properties are not presented as short, rigorous modalities, but rather as long expressions which, from a biological standpoint, totally capture the significance of the property, but which have the disadvantage of not being sufficiently manageable, from a mathematical standpoint. The interpretation of ecosystems through networks allows us to employ the concepts of coverage and invariance alongside other related concepts. The latter will allow us to present the two most important relations in an ecosystem - predator-prey and competition - in a different way. Biological control, defined as "the use of living organisms, their resources or their products to prevent or reduce loss or damage caused by pests", is now considered the environmentally safest and most economically advantageous method of pest control (Van Lanteren, 2011). A guild includes all those organisms that share a common food resource (Polis et al., 1989), which in the context of biological control means all the natural enemies of a given pest. There are several types of intraguild interactions, but the one that has received most research attention is intraguild predation, which occurs when two organisms share the same prey while at the same time participating in some kind of trophic interaction. However, this is not the only intraguild relationship possible, and studies are now being conducted on others, such as oviposition deterrence. In this article, we present statistical data to assess the effect of volatile compounds excreted by intra-and interspecific competitors on the oviposition behavior of female syrphids (Amoros-Jimenez, 2013) and we apply the developed concepts of structural functions, coverage, invariant sets, etc. (Lloret et al., 1998; Esteve and Lloret, 2006,a,b, 2007) to biological control in the specific case of a Mediterranean greenhouse.
\end{abstract}

Keywords Ecological network, Ecosystem, structural function, coverage, invariability.

\section{INTRODUCTION}

Ecological network analysis (ENA) is a systems-oriented methodology to analyze within system interactions used to identify holistic properties that are otherwise not evident from the direct observations. Ecological network analysis has been developed primarily using relatively small-scale, highly aggregated models (Hannon, 1973, 1979, 1986; Higashi and Burns, 1991; Higashi and Patten, 1989; Matis and Patten, 1981; Patten, 1985, 1991; Ulanowicz, 1986). Based on the results from these studies, Patten (1998) identified four network hypotheses or properties: amplification, homogenization, indirect effects dominance, and synergism (Fath and Patten, 1999). Network analysis is an important methodology that has been applied in systems ecology. Fath (2004) presents a way to develop large-scale cyber-models in order to test four of the main hypotheses of network analysis using models with a large number of compartments. There is no correct way to construct a network model, Fath et.al. (2007) try to offer some assistance for doing so, which hopefully will increase the number of networks that are developed. In ecosystems network, structure determines adjacent (direct) and non-adjacent (indirect) pathways over which energy, matter, and information can flow. Network structure establishes the pathways (direct and indirect) over which conserved material can flow between entities in connected systems (Fath and Patten, 1999). The relationship between pathway numbers and 
length is a significant component of this structure because it describes how quickly indirect pathways increase.

Ecological network research has correspondingly been dominated by networks of single interaction types (Bascompte, 2010), especially predator-prey networks or food webs. The relative neglect of non-predator-prey species interactions can have profound ramifications for our understanding of ecosystem function (Goudard and Loreau, 2008). Lin and Sutherland (2013) shows that for either general understanding or specific prediction of the dynamics of complex ecosystems, it is important to consider the role of environmental stochasticity and model such stochasticity in a way that mimics nature as closely as possible.

The creation and analysis of food-web models has been beneficial to the development of structural and functional relationships within both terrestrial and aquatic ecosystems. Elton (1927) introduced the idea of food pyramids as a result of observing characteristics of population dynamics within multiple ecosystems. In this paper, network analysis results indicate that the trophic distribution does not have a large effect on the overall network parameters, in that all parameters behaved qualitatively like the uniform distribution.

A sustainable system is one that continues more or less as it is over relatively long periods of time. A chaotic system is one that changes dramatically and unexpectedly from time to time, often for small reasons. According to Patten (1997), well-behaved dynamics considered to contribute to sustainability, and the opposite to chaos. Thus, from the standpoint of on-going life in ecosystems, sustainable processes will be seen as substantially 'well-behaved' and chaotic ones as, occasionally at least, 'poorly-behaved.' When chaos is asserted, surprise in the form of trajectory discontinuity or bifurcation occurs and sustainability is interrupted. Chaos may be either deterministic or indeterministic, and its mathematical basis is usually nonlinearity (Goerner, 1994).

In this paper we used the interpretation of ecosystems through networks. One benefit of the network perspective is that a large body of mathematics exists to help analyse many forms of networks models. If an ecosystem is modelled well, then it becomes possible to utilize relevant mathematical tools, such as graph theory, (Saura, S. and Pascual-Hortal, L., 2007) to better understand the way the ecosystem works. This interpretation allows us to employ the concepts of coverage and invariance alongside other related concepts. The latter will allow us to present the two most important relations in an ecosystem - predator-prey and competition - in a different way. As a case study, we analysed crops in the Mediterranean area, specifically a greenhouse located in the region of Murcia, Spain. Predator-prey and competition relations of the species under study have been previously demonstrated (Amoros-Jiménez, 2013).

\section{GREENHOUSE PESTS}

Today, agricultural crops are themselves regarded as a type of ecosystem. In these ecosystems, all of the types of interactions that exist between the living and non-living matter that makes up these ecosystems take place, which means that, as in any ecosystem, 
we find predator/prey relationships between species occupying different trophic levels and competition relationships between organisms at the same level.

Acquiring an understanding of the coverage and invariance of these relationships is both interesting and necessary because today pest control is an issue of great interest and relevance on account of the economic losses, environmental degradation, and potential health hazards attributable to pest infestation. For this reason, all aspects of this issue should be dealt with, so that we can ascertain where, with whom, how, and why pest infestation occurs, and, above all, so that we can reach the least harmful and most natural solution possible for everyone.

Pests, the most important of which are the arthropods, particularly insects, emerge in ecosystems that have suffered disruptions in their ecological balance, principally as a result of human activity. In particular, agricultural practices and the use of monoculture over large areas are the principal causes of the appearance of pests in this environment. One of the main effects of the loss of diversity associated with monoculture is the decline in the population and activity of agricultural pests' natural enemies, as a result of the destruction of habitats that provide these beneficial insects with indispensable food resources and overwintering sites (Corbett \& Rosenheim, 1996).

Important technological advances have occurred in this area, giving rise to a new era in pest control, but the implementation of these methods has paradoxically created new and even more severe problems.

Although initially the use of chemical products in agriculture was an enormously important and efficient strategy for controlling both major pest infestations as well as those involving lower economic losses, (Ramakers, 2004), these practices are being restricted to an increasing extent due to the serious consequences to which they give rise. As we are now beginning to understand, these products spread their toxic effects not only to the intended plant or insect but also eliminate from the environment plants and fauna that actually play an important and necessary role in the maintenance of the ecological balance, including the pests' natural enemies, which help to control them. In addition, these products affect the crop itself on specific occasions and are frequently highly toxic and persistent (Anonymous, 1995). In short, they 'solve' the problem over the short term but adversely impact the entire ecosystem over the long term.

In response to concerns raised by the above, attempts have been made to introduce new agricultural production systems that offer high quality products and reasonable profit margins while respecting the environment and its fauna to the greatest extent possible. In order to achieve this goal, we need only to observe what has always been there and is more ancient, if this is possible, than the problem itself; we need to make observations at those locations where the balance still occurs, where natural control exists, and then we need to thoroughly study the ecological relationships taking into account their biology, cycle, behaviour, phenology, and relationship type. The analysis of these relationships will allow us to develop the concepts of coverage and invariance so that, once their maximum potential is known, we can apply them in the area of interest, making use of the necessary 
means and knowledge that will enable us, in this manner, to neutralise, although almost never eradicate, those pest infestations for which we are ultimately responsible.

The mathematical study from this perspective could function as a very useful tool for creating programs for controlling and managing greenhouse pests.

\section{COVERAGE AND INVARIANCE IN ECOSYSTEMS}

Our basis for studying ecosystems was the General Systems Theory of Ludwig von Bertalanffy (1968) who defined a system as "a set of elements standing in interrelation among themselves and with the environment". We present the ecosystems, giving a simple view of them and avoiding the properties they have. We define an ecosystem as a pair consisting of living matter and/or non-living matter and by interactions with determination between said elements. Real determination is causative determination and causative interactions may be of two classes: transactions, with energy and matter changes; and relations, which are indirect consequences of transactions such as competition relation and predator-prey relation considered in this article. Between prey and predator, matter and energy flow together with information, but more information flows from predator to prey. This information is responsible for the evolution of the prey; the prey tends to evolve properties of immediate defensive utility, while the predator tends to evolve the capacity to learn and in general to manipulate more information (Margalef, 1991). As a living entity, we can understand, for example: plants (crops), aphids, aphidophagous insects. In other words, any living objects. A non-living matter could means, for example, water and nutrients.

Network theory starts with a square matrix of interactions where columns and rows are often a plant or animal, and the interactions represent animals eating each other or plants being eaten. The role of network theory in this article is replaced by the structural function and concepts of coverage and invariability. There is a distinction between structural function, coverage, invariability, and network theory. Network theory is quantitative, whereas structural function, coverage, and invariability are qualitative. In ecology, the term mathematical model refers to a formula, an equation, a system of equations, a matrix or an entire complex mathematical apparatus that allows us with sufficient accuracy to describe a phenomenon, characterize and/or simulate and predict in space and/or time the possible behaviors of ecosystems (Usó et al, 1995). The state equations in our model are represented by the structural function associated with competition and predation relationships, and a mathematical formalization of the model is presented online (LloretCliment and Nescolarde-Selva, 2014). For statistical analysis (Amorós-Jimenez, 2013), olfactometer choices were analyzed using a log linear model that takes into account over dispersion. All data were analysed with the statistical packages R and SPSS. The structural function associated with the competition relation assigns to the state variable of each competitor the set of all of its competitors. Thus, any living entity or non-living matter is associated with the set of all the entities that compete with it. The structural function associated with the predatory relation assigns to the state variable of any predator with the set of all its preys. Any predator is associated with the set of all its preys. These functions behave differently when acting upon the sets: ecosystem's predators, ecosystem's preys and 
ecosystem's competitors. In general they fulfil the following conditions, even though their functions may vary in each ecosystem: (See, Table 1 and 2)

\begin{tabular}{|l|l|l|l|l|l|l|l|l|}
\hline DOMAIN/RANGE & M.e & M.p & A.s & A.cr & C.a & V.f & C.s & $\begin{array}{l}\text { Water } \\
\text { and } \\
\text { Nutrients }\end{array}$ \\
\hline A.b & $\mathrm{x}$ & $\mathrm{x}$ & $\mathrm{x}$ & $\mathrm{x}$ & & & & \\
\hline S.r & $\mathrm{x}$ & $\mathrm{x}$ & $\mathrm{x}$ & $\mathrm{x}$ & & & & \\
\hline A.co & $\mathrm{x}$ & $\mathrm{x}$ & $\mathrm{x}$ & $\mathrm{x}$ & & & & \\
\hline M.e & & & & & $\mathrm{x}$ & $\mathrm{x}$ & $\mathrm{x}$ & \\
\hline M.p & & & & & $\mathrm{x}$ & $\mathrm{x}$ & $\mathrm{x}$ & \\
\hline A.s & & & & & $\mathrm{x}$ & $\mathrm{x}$ & $\mathrm{x}$ & \\
\hline A.cr & & & & & $\mathrm{x}$ & $\mathrm{x}$ & $\mathrm{x}$ & \\
\hline C.a & & & & & & & & $\mathrm{x}$ \\
\hline V.f & & & & & & & & $\mathrm{x}$ \\
\hline C.s & & & & & & & & $\mathrm{x}$ \\
\hline
\end{tabular}

Table 1: Values of the state equation of the structural function associated with the predatorprey relation.

\begin{tabular}{|l|l|l|l|l|l|l|l|l|l|l|}
\hline DOMAIN/RANGE & A.b & S.r & A.co & M.e & M.p & A.s & A.cr & C.a & V.f & C.s \\
\hline A.b & $\mathrm{x}$ & $\mathrm{x}$ & $\mathrm{x}$ & & & & & & & \\
\hline S.r & $\mathrm{x}$ & $\mathrm{x}$ & $\mathrm{x}$ & & & & & & & \\
\hline A.co & $\mathrm{x}$ & $\mathrm{x}$ & $\mathrm{x}$ & & & & & & & \\
\hline M.e & & & & $\mathrm{x}$ & $\mathrm{x}$ & $\mathrm{x}$ & $\mathrm{x}$ & & & \\
\hline M.p & & & & $\mathrm{x}$ & $\mathrm{x}$ & $\mathrm{x}$ & $\mathrm{x}$ & & & \\
\hline A.s & & & & $\mathrm{x}$ & $\mathrm{x}$ & $\mathrm{x}$ & $\mathrm{x}$ & & & \\
\hline A.cr & & & & $\mathrm{x}$ & $\mathrm{x}$ & $\mathrm{x}$ & $\mathrm{x}$ & & & \\
\hline C.a & & & & & & & & $\mathrm{x}$ & $\mathrm{x}$ & $\mathrm{x}$ \\
\hline V.f & & & & & & & & $\mathrm{x}$ & $\mathrm{x}$ & $\mathrm{x}$ \\
\hline C.s & & & & & & & & $\mathrm{x}$ & $\mathrm{x}$ & $\mathrm{x}$ \\
\hline
\end{tabular}

Table 2: Values of the state equation of the structural function associated with the competition relation.

A) When the structural function associated with predator-prey relation acts on the set of predators, we obtain the set of prey of these predators.

B) When the structural function associated with predator-prey relation acts on the set of competitors, we obtain the set of prey of these competitors.

C) When acts on the set of preys, we obtain the prey set of these preys.

D) When the structural function associated with the competition relation acts upon the set of predators, we obtain at least the same set of predators, given that the predators 
set competes for the same set of preys. The exception would be the case of an ecosystem in which one of the predators does not compete with any other predator for one or several preys. In this case, from the mathematical standpoint, the function requirement obliges us to eliminate this predator from the domain of function.

E) When the structural function associated with the competition relation acts upon the set of preys, we obtain at least the same set of preys, given that the set of preys competes to avoid the same set of predators. The exception would be the case of an ecosystem in which one of the preys does not compete with any other prey as the target of one or more predators. In this case, from the mathematical standpoint, the function requirement obliges us to eliminate this prey from the domain of function.

F) When the structural function associated with the competition relation acts upon the set of competitors, we obtain the same set of competitors.

The classical approach to the problem of ecosystem behaviour in ecological theory has been to model the interaction of two organisms with detailed, complex, nonlinear differential equations. Using the same methodology for cases involving more than two interacting organisms results in formulations that are often intractable. The concepts of coverage and invariability are necessary to better explain observed phenomena, predict effects of disturbances, and provide a more reliable basis for possible ecosystem management.

For two sets of living entities and/or non-living matter, we will say that the first set covers the second set if when the structural function associated with any relation acts on the first set, we obtain the second set. This concept appears with all of its ramifications in the predator-prey relation, with regard to which we can affirm that the set of predators found in an ecosystem covers the set of prey. (See Fig. 1)

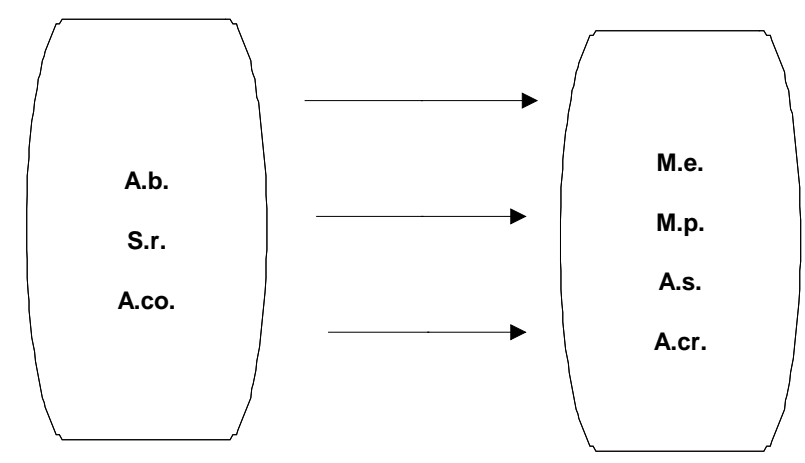

Figure 1. Coverage between sets for the relation of depredation

We will say that a set is invariant when the structural function associated with any relation acts on the set; we obtain a subset of the initial set. The concept of invariance can be interpreted as a type of endogamy between the elements of a single set, which are only going to relate to each other, maintaining the set's structure and status in respect of any type of relation. The characteristic example of an invariable set is the set of competitors in an ecosystem. (See Fig. 2) 


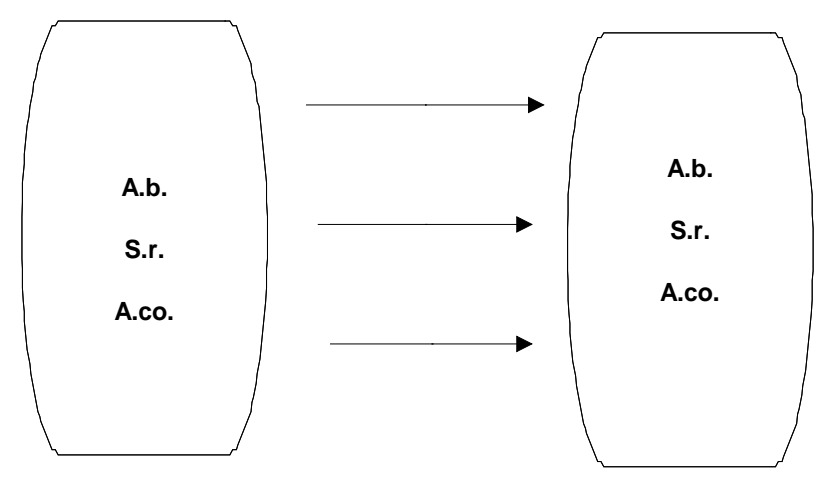

Figure 2. Invariant set for the relation of competition

The inclusions among invariant sets for the practical case of a greenhouse are shown in Figure 3.

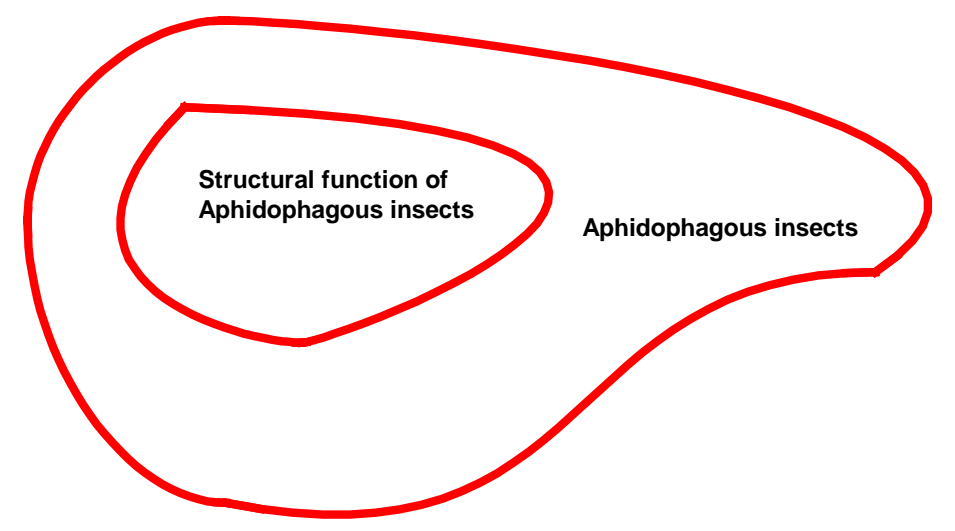

Figure 3. Inclusion between invariant sets for the relation of competition

The advantage of using the concepts of coverage and invariability to deal with these issues is that they enable us to use a mathematical function, and in this manner, it makes sense to work with unions and intersections or to create varied compositions of the structural function over different sets. In this manner, we are creating a Mathematical Formulation of Ecological Systems which uses the concepts of coverage and invariability to obtain conclusions regarding the behaviour of these sets.

We start by proving a series of immediate results stemming from the previous definition. (See Figure 4). 


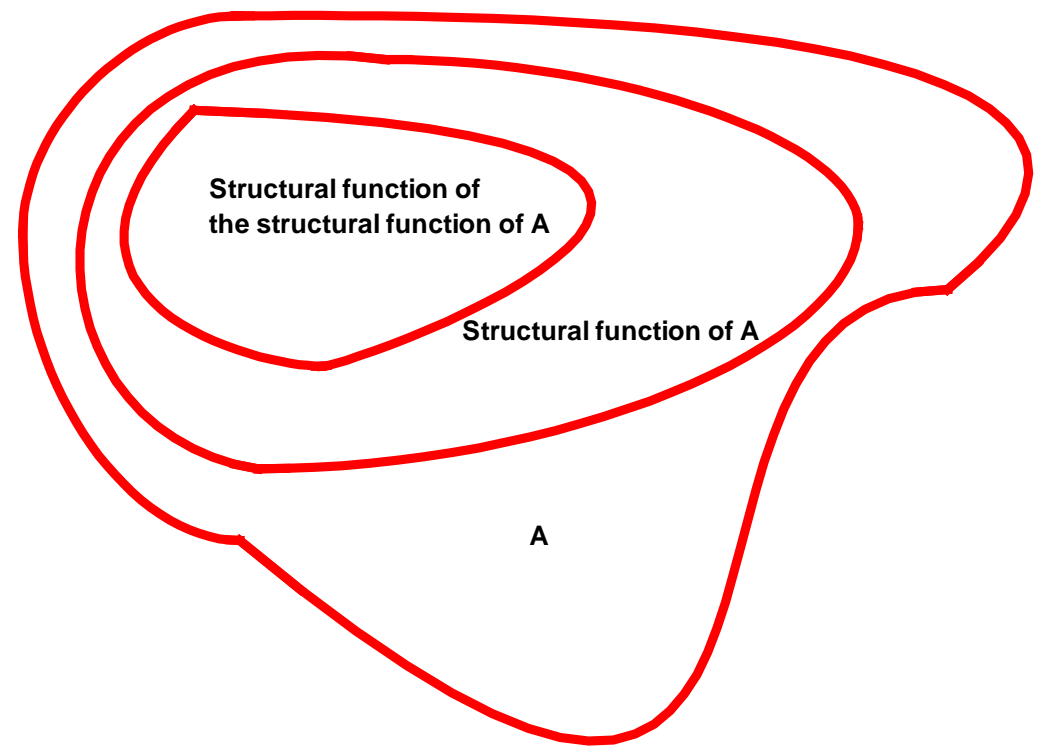

Figure 4. Structural function associated with the competition relations acts on the set A of predators.

A) If the set of predators with the competition relation is invariant, the set "Structural function associated with the competition relation acts on the set of predators" is also invariant.

B) If the set of preys with the competition is invariant, the set "Structural function associated with the competition relation acts on the set of preys" is also invariant.

C) If the set of competitors with the competition relation is invariant, the set "structural function associated with the competition relation acts on the set of preys" is also invariant.

From the previous results, we obtain the following consequences: If the set of predators is invariant, any iteration of the structural function associated with the competition relation over predators will also be invariant. Similar results are obtained by replacing the set of predators with the set of preys or the set of competitors.

The following are some results about the behaviour of invariant sets. (See Figure 5)

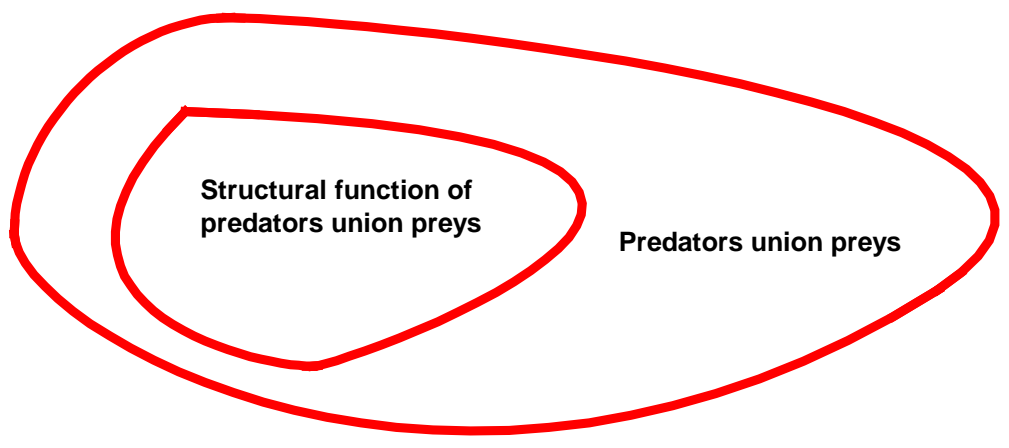


Figure 5. The union of predators and preys.

A) When the sets of predators and preys are both invariant with the competition relation, the union of predators and preys is invariant.

B) Likewise, by combining the sets of predators and competitors, preys and competitors, and the predators, preys and competitors sets we obtain similar results.

Analogous results are obtained with the intersection of the invariable sets. (See Figure 6)

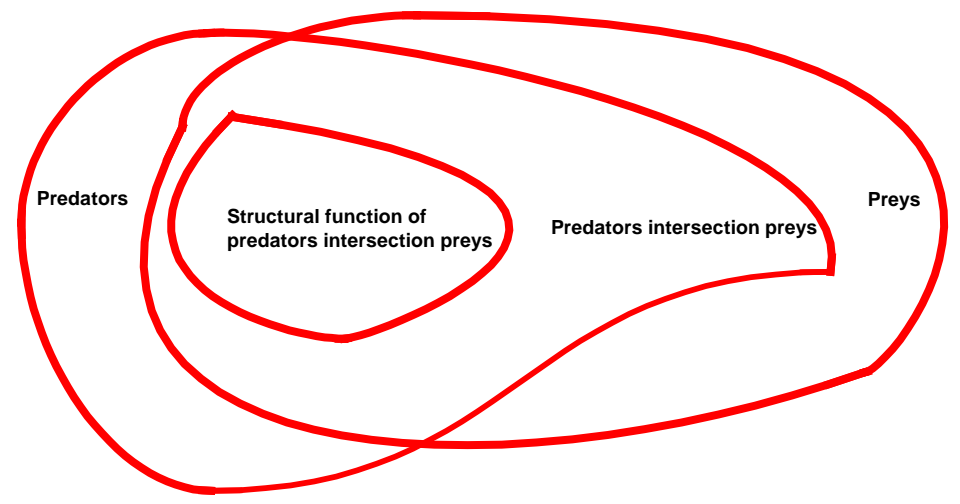

Figure 6. The intersection of predators and preys

A) When the sets of predators and preys are both invariant, with the competition relation, the not disjoint intersection of predators and preys is invariant.

B) Likewise, combining the predator and competitor sets, the prey and competitor sets, and the predators, prey and competitor sets we obtain similar results.

The following statement confirms how the concepts of coverage and invariability can act jointly:

When the set of preys is invariant, with the predator-prey relation and the set of predators covers the set of preys, then the union of predators and preys will be invariant and under the same conditions as above, the set of predators and preys covers the set of preys.

\section{ANALYSIS OF A MEDITERRANEAN GREENHOUSE}

The majority of the European production of horticultural crops originates in the Mediterranean basin (FAOSTAT, 2009). Specifically, this region includes the largest area of greenhouse-produced horticultural crops in the world (Espí et al., 2006). These crops, such as sweet peppers for example (Capsicum anuum L.) (Solanaceae), are affected by a range of pests with variable financial losses, of which some of the principal types include white flies, aphids, and lepidoptera (Pineda, 2008). 
The variables considered in the greenhouse include: non-living matter composed of nutrients and water, which constitute level 1.

Living entities, plants (crops), constitute level 2: pepper (Capsicun annum), cucumber (Cucumis sativus) and beans (Vicia faba).

Aphids (Hemiptera: Aphididae) are one of the most destructive pests with regard to greenhouse crops, particularly horticultural, with regard to which they are the principal source of infestation (Ramakers, 2004). These insects cause great harm directly to plants by consuming the phloem sap and indirectly by producing large quantities of treacle, which remains deposited on fruits and leaves, fostering the development of fungi, and by acting as vectors for viruses that cause enormous declines in production (Rabasse and Steenis, 2002; Blümel, 2004; Katis et al., 2007; Byers, 2008). Aphids are level 3 herbivores: Aulacorthum solana, Aphis cracciovora, Macrosiphum euphorbiae and Mizus persicae are polyphagous species that compete among themselves for the plants specified above. Aphid populations are characterised by a very rapid exponential growth rate, as a result of which competition among them is intense.

Due to the high probability that resistances to the few chemical products available will develop, there is a great demand for new strategies based on Biological Control that will be effective against aphid infestation in greenhouse horticultural crops (Sánchez et al., 2011). Until now, the majority of the arthropods used in augmentative biological control have been hymennopterous parasites (van Lenteren, 2011), such as Aphidius colemani, because they share a trait that is considered an essential criterion when selecting a natural enemy: their high level of host specificity or narrow host range. Nevertheless, there are also predators that fulfil this condition. In fact, hundreds or even thousands of potential natural enemies remain to be discovered, and a high success rate is being achieved with the use of newly discovered agents (Van Lenteren, 2011). Phytophagous syrphids (Diptera: Syrphidae) are agents considered to have enormous potential in the biological control of aphids (Tenhumberg and Poehling, 1995; Rojo et al., 2003; Brewer and Elliott, 2004; Freier et al., 2007; Haenke et al., 2009). Although many of the articles on their importance for biological control focus on outdoor crops (Niehoff and Poehling, 1995; Jansen, 2000; Miñarro et al., 2005; Aguado et al., 2006; Freier et al., 2007; Diaz et al., 2010), an increasing number of studies also demonstrate their importance for greenhouse crops (Pineda and Marcos-García, 2008b; Pineda and Marcos-García, 2008a; Pineda and Marcos-García, 2008b). Sphaerophoria rueppellii (Diptera: Syrphidae) is an aphido-phagous syrphid of Paleartic distribution but is particularly common in crops in the Mediterranean area (Speight, 2005). Its adaptation to the warm Mediterranean climate has made it a suitable species for pest control in this region (Pineda, 2008), and its biology, interactions and use have been researched and tested recently with regard to the biological control of infestations resulting from different species of aphids such as Myzus persicae or Ropallosiphun padii (AmorósJiménez, 2013).

Level 4 predators include three aphidophagous insects that compete with each other to consume aphids: 
Predatory syrphid (Sphareophoria rueppelli): it consumes aphids in the larvae phase (L1, L2, L3). Adults are pollinators.

Predatory ladybird (Adalia bipunctata): Both larvae and adults consume aphids. Adults can be somewhat more polyphagous.

Parasitoid (Aphidius colemani): In this case only larvae consume aphids, but from the inside out because the female deposits an egg inside the body of the aphid. When the adult emerges, the aphid dies leaving behind an aphid 'mummy'.

The situation proposed in the greenhouse appears in figure 7:

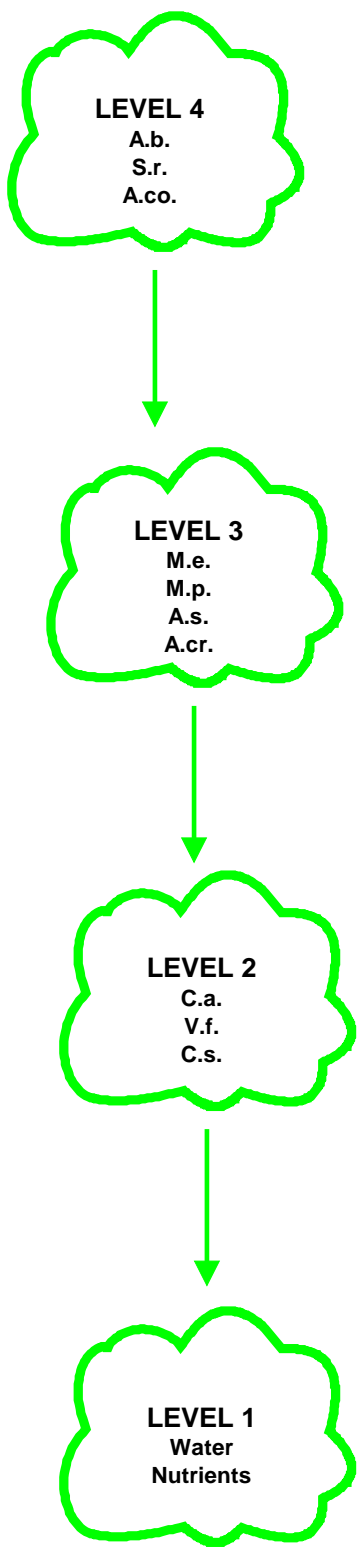

Figure 7. Levels of the greenhouse

Legend: C.a: Capsicun annum; C.s: Cucumis sativus; V.f: Vicia faba; A.s: Aulacorthum solani; A.cr: Aphis cracciovora; M.e: Macrosiphum euphorbiae; M.p: Myzus persicae; S.r: Sphaerophoria rueppelli; A.b: Adalia bipunctata; A.co: Aphidius colemani. 
The 4 levels of the greenhouse are represented. Intra-level relationships involve competition while inter-level relationships are predator-prey. Entities at the same level are invariant. Entities at a specific level cover the entities at the preceding level.

In this greenhouse, we will analyse predator-prey relationships and competition from a different point of view, putting forward the concepts of coverage and invariance and analysing their meaning.

The greenhouse ecosystem is composed of living entities, the non-living matter described above, predator-prey relationships, and relationships based on competition. The direct relationships between entities are relationships of pairs; for example, the living entity, the pepper plant, is a 'predator' in respect of non-living matter, water. Generalising this relationship between pairs, we obtain the indirect relationship; for example, the ladybird is an indirect predator with regard to nutrients.

These concepts form the basis for interpreting the structural functions associated with predator-prey and competition relationships: The competition function associates each entity with the group comprising all of the entities that compete with the former: Hence, the competition function associated with the pepper would be composed of cucumbers and beans. The depredation function associates each entity with the group comprising all of its prey: the depredation function of the parasitoid would be the group consisting of all aphids.

These functions can act with several entities, as a result of which it makes sense to discuss competition and depredation functions associated with the group consisting of predators, prey, and competitors, with these functions serving as a foundation for the concepts of coverage and invariance between different groups.

The concepts of coverage and invariance in a greenhouse are defined as follows: When as a result of applying one of these functions in a group of entities another group of entities is obtained, we will say that the first group covers the second. The coverage between groups is entirely connected to the depredation relationship since when we act on a group of predators at one level, we obtain the group of prey at the preceding level. Hence, when we act on ladybirds, syrphids, and parasitoids, we obtain all types of aphids, as a result of which level 4 predators cover level 3 aphids. When we act on aphids, we obtain plants, as a result of which aphids cover plants, and when we act on plants, we obtain non-living matter; in other words, plants cover non-living matter.

When we apply these functions to a group of entities and obtain a portion of the same group, the group is said to be invariant. Invariant groups are connected to the competition relationship since when we act on a group of entities at the same level, we obtain entities at the same level. Hence, the group composed of level 4 predators, the group composed of aphids, and the group composed of crops would be examples of invariant groups with regard to the competition relationship. (Figure 7).

The properties proposed in the above paragraph can be developed for the case of the greenhouse: Among these, we mention that the predator group: \{syrphid, ladybird, 
parasitoid and to the prey group: \{aphids\}, given that both groups are invariant, allows us to deduce that the joint group of predators and aphids will also be invariant for the competition relationship. This can be generalized for different connections between a range of groups.

The intersection also functions between different types of groups; hence, we could consider aphids as prey and competitors, which is an invariant group for the competition relationship, and the intersection, which is again the same aphid group, is invariant.

The most important properties in the greenhouse are established when the two analysed relationships are involved or when the concepts of coverage and invariance are jointly involved. Hence, we can consider the whole group of predators: \{ladybird, parasitoid, syrphid, aphid, pepper, cucumber, beans \} and the whole group of prey: \{aphid, pepper, cucumber, beans, water, nutrients\}. The first predator group covers the prey group; therefore, the joint group containing all of the entities is invariant.

These properties illustrate the ecological importance of the concepts of coverage and invariance because they allow us to study the typical relationships occurring in an ecosystem in a much more precise manner. Furthermore, these concepts can be extrapolated to the analysis of other ecosystem relationships.

\section{CONCLUSION}

In this article, the structural functions associated with ecosystem relations, along with the concepts of coverage and invariance, allow us to make a different, original presentation of ecosystems.

This model has been applied to the previously mentioned specific case of pest analysis in a Mediterranean greenhouse where it was shown that all of the appearing sets fulfil all of the properties and the interactions between sets are supported by previous statistical analyses (Amoros-Jimenez, 2013).

One benefit of the network perspective is that a large body of mathematics exists to help analyze many forms of networks models. If an ecosystem is modelled well, then it becomes possible to utilize relevant mathematical tools, such as graph theory, to better understand the way the ecosystem works. The role of network theory in this article is replaced by structural function and the concepts of coverage and invariance obtained from graph theory. There is a distinction between structural function, coverage, invariability, and network theory. Network theory is quantitative, whereas structural function, coverage, and invariability are qualitative.

The advantage of using the concepts of coverage and invariability to deal with these issues instead of analysing the ecosystem relations from a classical point of view is that they enable us to use a mathematical function and in this manner it makes sense to work with unions and intersections or to create varied compositions of the structural function over different sets as is demonstrated by the results and figures presented in this article. We are 
creating a Mathematical Formulation of Ecological Systems which uses the concepts of coverage and invariability to obtain conclusions regarding the behaviour of these sets. The majority of the analytical techniques are based on a mathematical modelling process which does not always faithfully reflect the real model. On the other hand, the type of analysis involving coverage and invariability is accurately based on the real behaviour of the ecosystem.

Patten (1991), in his concluding remarks, quotes: 'I have been invited by the editors to give a personal perspective on the future of network approaches in ecology. I have chosen to do this by focusing on what seems to be the key manifestation of the operation of ecological networks, and what might not occur without them-indirect effects'.

The indirect affects appear in the compositions of the structural function over the concepts of coverage and invariability. The successive iterations tell us what the ecosystem is evolving towards. This can be utilized in the analysis of other questions such as diversity within an ecosystem, because if one important part of the ecosystem shows invariance, this really means that the part maintains its status, remaining constant in the face of changes and thereby diminishing the ecosystem's diversity.

\section{REFERENCES}

Amorós-Jiménez, H. R. 2013. Biología, interacciones y uso del depredador Sphaerophoria rueppellii (Diptera: Syrphidae) en el Control Integrado de plagas de áfidos en cultivos de invernadero. Doctoral Thesis, University of Alicante, Alicante, Spain.

Anonymous. 1995. Montreal protocol on substances that deplete de ozone layer. Report of the Methyl Bromide Technical Option Comitee. UNEP, Kenya.

Bascompte, J., 2010. Structure and dynamics of ecological networks. Science 329, 765766.

Bertalanffy L.V. (1968). General Systems Theory. Foundations, Development,Applications. George Braziller, New York.

Bigler, F., Babendreier, D., Kuhlmann, U. 2006. Environmental Impact of Invertebrates for Biological Control of Arthropods Methods and Risk Assessment Preface. Cabi PublishingC a B Int, Wallingford.

Brewer, M.J., Elliott, N.C. 2004. Biological control of cereal aphids in North America and mediating effects of host plant and habitat manipulations. Annual Review of Entomology 49, 219-242.

Byers, J.A. 2008. Aphids as Crop Pests. CABI, London, UK, Nosworthy Way, Wallingford, Oxfordshire. 
Corbett, A., Rosenheim, J.A., 1996. Impact of natural enemy overwintering refuge and its interaction with the surrounding landscape. Ecological Entomology 21:155-164.

Diaz, B.M., Legarrea, S., Marcos-Garcia, M.A., Fereres, A. 2010. The spatio-temporal relationships among aphids, the entomophthoran fungus, Pandora neoaphidis, and aphidophagous hoverflies in outdoor lettuce. Biological Control 53, 304-311.Elton, C., 1927. Animal Ecology. Sudgwick \& Jackson, London.

Espí, E., Salmerón, A., Fontecha, A., García, Y., Real, A.I. 2006. Plastic films for agricultural applications. Journal of Plastic Film \& Sheeting 22, 85-102.

Esteve, P.F., and Lloret, M., 2006. Coverage, invariability and orbits by structural functions. Kybernetes. 35(7/8), 1236-1240.

Esteve, P.F., and Lloret, M., 2006. Coverage and invariability by structural functions. International Journal of General Systems. 35(6): 699-706.

Esteve, P.F., and Lloret, M., 2007. Attractors, structural functions and the water cycle. Cybernet. Syst. Int. J., 38(4), 401-409.

Fath, B.D., Patten, B.C., 1999. Review of the foundations of network environ analysis. Ecosystems 2, 167-179.

Fath, B.D., 2004. Network analysis applied to large-scale cyber-ecosystems. Ecol. Model. 171, 329-337.

Fath, B.D., Scharler, U.M., Ulanowicz, R.E., Hannon, B. 2007. Ecological network: network construction. Ecol. Model. 208, 49-55.

Freier, B., Triltsch, H., Mowes, M., Moll, E. 2007. The potential of predators in natural control of aphids in wheat: Results of a ten-year field study in two German landscapes. BioControl 52, 775-788.

Goerner, S.J., 1994. Chaos and the Evolving Ecological Universe. Gordon and Breach, Luxembourg.

Goudard, A., Loreau, M., 2008. Nontrophic interactions, biodiversity, and ecosystem functioning: an interaction web model. American Naturalist 171, 91-106.

Hannon, B., 1973. The structure of ecosystems. J. Theor. Biol. 41, 535-546.

Hannon, B., 1979. Total energy costs in ecosystems. J. Theor. Biol. 80, 271-293.

Hannon, B., 1986. Ecosystem control theory. J. Theor. Biol. 121, 417-437. 
Higashi, M., Patten, B.C., 1989. Dominance of indirect casuality in ecosystems. Am. Nat. 133, 288-302.

Higashi, M., Burns, T.P. (Eds.), 1991. Theoretical Studies of Ecosystems: The Network Perspective. Cambridge University Press, New York.

Katis, N.I., Tsitsipis, J.A., Stevens, M., Powell, G. 2007. Transmission of Plant Viruses. In: van Emdem, H.F., Harrington, R., Eds.), Aphids as Crop Pests. CABI Publishing, Wallingford.

Lin, Y., Sutherland, W.J. 2013. Color and degree of interspecific synchrony of environmental noise affect the variability of complex ecological networks. Ecol. Model. 263, 162-173.

Lloret, M., Villacampa, Y. and Usó, J.L., 1998. System-linkage: structural functions and hierarchies. Cybernet. Syst. Int. J. 29, 29-39.

Lloret, M. and Esteve, P.F. 2007. A systemic theory of orbits in ecological networks. Kybernetes, 36 (3/4), 469-475.

Lloret-Climent, M. and Nescolarde-Selva, J. (2014), Data analysis using circular causality in networks. Complexity, 19(4). pp 15-19.

Margalef, R. 1991. Theoretical studies of ecosystems. In M. Higashi, \& T. P. Burns. Networks in ecology (pp. 41-57). Cambridge University Press.

Matis, J.H., Patten, B.C., 1981. Environ analysis of linear compartmental systems: the static, time invariant case. In: Proceedings of the 42nd Session of International Statistical Institute, Manila, Phillipines, 4-14 December 1979.

Patten, B.C., 1985. Energy cycling in the ecosystem. Ecol. Model. 28, 1-71.

Patten, B.C., 1991. Network ecology: indirect determination of the life-environment relationship in ecosystems. In: Higashi, M., Burns, T. (Eds.), Theoretical Studies of Ecosystems: The Network Perspective. Cambridge University Press, New York.

Patten, B. C. 1991. Theoretical studies of ecosystems. In M. Higashi, \& T. P. Burns. Concluding Remarks (pp. 288-352). Cambridge University Press.

Patten, B.C. 1997. Synthesis of chaos and sustainability in a nonstationary linear dynamic model of the American black bear (Ursus americanus Pallas) in the Adirondack Mountains of New York. Ecol. Model. 100, 11-42.

Patten, B.C., 1998. Steps toward a cosmography of ecosystems: 20 remarkable properties of life in environment. In: Mueller, F., Leupelt, M. (Eds.), Eco Targets, Goal Functions, and Orientors. Springer-Verlag, New York. 
Patten B.C., 2003. Holoecology: The Unification of Nature by Network Indirect Effects. Complexity in Ecological Systems Series. Columbia University Press, New York.

Pimentel, D. 2009. Environmental and Economic Costs of the Application of Pesticides Primarily in the United States. Springer, Po Box 17, 3300 Aa Dordrecht, Netherlands.

Pineda, A. 2008. Los sírfidos (Diptera: Syrphidae) en el integrado de plagas de pulgón en cultivos de pimiento de invernadero. Doctoral Thesis. Universidad de Alicante. 172p.

Pineda, A., Marcos-Garcia, M.A. 2008a. Introducing barley as aphid reservoir in sweetpepper greenhouses: Effects on native and released hoverflies (Diptera : Syrphidae). European Journal of Entomology 105, 531-535.

Pineda, A., Marcos-Garcia, M.A. 2008b. Use of selected flowering plants in greenhouses to enhance aphidophagous hoverfly populations (Diptera: Syrphidae). Annales De La Societe Entomologique De France 44, 487-492.

Polis, G.A., Myers, C.A. and Holt R.D. 1989. The ecology and evolution of intraguild predation: potential competitors that eat each other. Annual Review of Ecology and Systematic, 20: 297-330.

Rabasse, J.M., Steenis, M.J. 2002. Biological Control of Aphids. In: Albajes, R., Lodovica Gullino, M., Lenteren, J.C., Elad, Y., Eds.), Integrated Pest and Disease Management in Greenhouse Crops. Springer Netherlands, pp. 235-243.

Ramakers, P.M.J., 2004. IPM Program for sweet pepper. In: Heinz, K.M., van Driesche, R.G., Parrella, M.P. (Eds.), Biocontrol in protected culture. Ball Publishing, Batavia, pp. 439-456.

Rojo, S., Gilbert, F., Marcos-García, M.A., Nieto, J.M., Mier, P.M. 2003. A world review of predatory hoverflies (Diptera, Syrphidae: Syrphinae) and their prey. CIBIO Ediciones, Alicante (Spain).

Sánchez, J.A., La-Spina, M., Michelena, J.M., Lacasa, A., de Mendoza, A.H. 2011. Ecology of the aphid pests of protected pepper crops and their parasitoids. Biocontrol Science and Technology 21, 171-188.

Saura, S., Pascual-Hortal, L. 2007, CONEFOR SENSINODE 2. 2. User's Manual: Software for Quantifying the Importance of Habitat Patches for Maintaining Landscape Connectivity through Graphs and Habitat Available Indices. University of Lleida, Lleida, Spain.

Speight, M.C.D. 2005. Species accounts of European Syrphidae (Diptera). In: Speight, M.C.D., Castella, E., Sarthou, J.-P., Monteil, C., Eds.), Syrph the Net, the database of European Syrphidae. Syrph the Net Publications, Dublin, Ireland. 
Tenhumberg, B., Poehling, H.M. 1995. Syrphids as Natural Enemies of Cereal Aphids in Germany - Aspects of Their Biology and Efficacy in Different Years and Regions. Agriculture Ecosystems \& Environment 52, 39-43.

Ulanowicz, R.E., 1986. Growth and Development: Ecosystem Phenomenology. SpringerVerlag, New York.

Usó-Domènech, J.L., Villacampa, Y., Stübing, G., Karjalainen, T. \& Ramo, M.P. 1995. MARIOLA: a model for calculating the response of mediterranean bush ecosystem to climatic variations. ECOLOGICAL MODELLING. 80, 113-129.

van Lenteren, J.C., Bueno, V.H.P. 2003. Augmentative biological control of arthropods in Latin America. BioControl 48, 123-139.

van Lenteren, J. 2011. The state of commercial augmentative biological control: plenty of natural enemies, but a frustrating lack of uptake. BioControl, 1-20.

van Lenteren, J.C., Manzaroli, G. 1999. Evaluation and use of Predators and Parasitoids for Biological Control of Pests in Greenhouses. In: Albajes, R., Lodovica Gullino, M., Lenteren, J.C., Elad, Y., Eds.), Integrated Pest and Disease Management in Greenhouse Crops. Springer Netherlands, pp. 183-201. 